\title{
Evaluation of a Modified MPA Procedure Assuming Higher Modes as Elastic to Estimate Seismic Demands
}

\author{
Anil K. Chopra, University of California, Berkeley, \\ Rakesh K. Goel, California Polytechnic State University, San Luis Obispo, \\ and Chatpan Chintanapakdee, Chulalongkorn University, Bangkok
}

\begin{abstract}
The modal pushover analysis (MPA) procedure, which includes the contributions of all significant modes of vibration, estimates seismic demands much more accurately than current pushover procedures used in structural engineering practice. Outlined in this paper is a modified MPA (MMPA) procedure wherein the response contributions of higher vibration modes are computed by assuming the building to be linearly elastic, thus reducing the computational effort. After outlining such a modified procedure, its accuracy is evaluated for a variety of frame buildings and ground motion ensembles. Although it is not necessarily more accurate than the MPA procedure, the MMPA procedure is an attractive alternative for practical application because it leads to a larger estimate of seismic demands, improving the accuracy of the MPA results in some cases (relative to nonlinear response history analysis) and increasing their conservatism in others. However, such conservatism is unacceptably large for lightly damped systems, with damping significantly less than 5\%. Thus the MMPA procedure is not recommended for such systems.
\end{abstract}

\section{INTRODUCTION}

Now standard in structural engineering practice (ASCE 2001), the nonlinear static procedure (NSP) or pushover analysis is used to estimate seismic demands for buildings. This procedure subjects a building to monotonically increasing lateral forces with an invariant height-wise distribution until a predetermined target displacement is reached. Both the force distribution and target displacement are based on two assumptions: (1) the response is controlled by the fundamental vibration mode, and (2) the mode shape remains unchanged after the structure yields.

Both these assumptions have inherent limitations that can severely affect the accuracy of the results. To address the second limitation, several researchers have proposed adaptive force distributions that follow more closely the time-variant distributions of inertia forces (Bracci et al. 1997, Gupta and Kunnath 2000). Attempts have been made to address the first assumption by considering more than the fundamental vibration mode 
in pushover analysis (Gupta and Kunnath 2000, Paret et al. 1996, Sasaki et al. 1998, Kunnath and Gupta, 2000, Matsumori et al. 2000). Recently, Chopra and Goel (2002) have developed a pushover analysis procedure - the modal pushover analysis (MPA) that includes the contributions of all modes of vibration that contribute significantly to the seismic demand. This procedure has been improved, especially in its treatment of P- $\Delta$ effects due to gravity loads, by including them in all modes. The improved version of MPA is summarized in Goel and Chopra (2004).

The MPA procedure estimates seismic demands much more accurately than current pushover procedures used in structural engineering practice (Goel and Chopra 2004, Chopra and Chintanapakdee 2004a). This improved accuracy is achieved without any significant increase in computational effort. Pushover analyses for the first two or three "modal" force distributions are typically sufficient in the MPA procedure; this is comparable to the computational effort for the FEMA-356 procedure, which requires pushover analysis for at least two force distributions.

Nevertheless, it is attractive to explore the possibility of reducing the computational effort in MPA by simplifying computation of the response contributions of higher vibration modes by assuming the building to be linearly elastic, an idea that has been utilized earlier for other applications (Eberhard and Sozen 1993, Rodriguez et al. 2002). The objective of this paper is to evaluate the accuracy of such a modified modal pushover analysis procedure for a variety of frame buildings and ground motion ensembles.

\section{STRUCTURAL SYSTEMS, GROUND MOTIONS, AND RESPONSE STATISTICS}

\section{STRUCTURAL SYSTEMS AND GROUND MOTIONS}

Two sets of structural systems and ground motions are considered. The first set is generic one-bay frames of six different heights: $3,6,9,12,15$, and 18 stories; the bay width is $24 \mathrm{ft}$ and story height is $12 \mathrm{ft}$. The height-wise distribution of stiffness is defined to achieve equal drifts in all stories under the lateral forces specified in the International Building Code (IBC) (ICC 2000). Assuming that the second moment of crosssectional area for each beam and its supporting columns in the story below are the same, numerical values for the flexural rigidities of structural elements were selected such that the fundamental vibration period is defined as being $T_{U}=0.045 H^{0.8}$, the mean-plus-onestandard-deviation of measured periods (Goel and Chopra 1997). Additional description for the frames is available in Chintanapakdee and Chopra (2002) where frames with

$T_{L}=0.028 H^{0.8}$, the mean-minus-one-standard-deviation of data, were also analyzed but these results, which are consistent with those presented here, are not included here for brevity. The frames are designed according to the strong column-weak beam philosophy; therefore, plastic hinges form only at beam ends and the base of the first-story columns. Bending moment yield strength distribution is designed such that yielding occurs simultaneously at all plastic hinges under the $I B C$ lateral force distribution. The yield base shear is selected as $V_{b y}=\left(A_{y} / g\right) W$, where $W$ is the total weight of the frame, and $A_{y}$ is the median (over 20 ground motions) pseudo-acceleration for a single-degree-of-freedom (SDF) system with vibration period $T_{n}=T_{1}$ and ductility factor $\mu=1,1.5,2,4$, and 6 , i.e., five different designs are considered for each frame height. 
Table 1. Modal periods and damping ratios for six SAC buildings

\begin{tabular}{|c|c|c|c|c|c|c|c|c|c|c|}
\hline \multirow[b]{2}{*}{ Building } & \multicolumn{5}{|c|}{ Modal Period (sec) } & \multicolumn{5}{|c|}{ Modal Damping Ratio (\%) } \\
\hline & $T_{1}$ & $T_{2}$ & $T_{3}$ & $T_{4}$ & $T_{5}$ & $\zeta_{1}$ & $\zeta_{2}$ & $\zeta_{3}$ & $\zeta_{4}$ & $\zeta_{5}$ \\
\hline Boston 9-Story & 3.11 & 1.16 & 0.696 & 0.476 & 0.350 & 1.88 & 0.983 & 0.936 & 1.11 & 1.28 \\
\hline Seattle 9-Story & 2.99 & 1.08 & 0.590 & 0.375 & 0.259 & 1.90 & 0.990 & 0.988 & 1.23 & 1.61 \\
\hline Los Angeles 9-Story & 2.27 & 0.852 & 0.493 & 0.327 & 0.240 & 1.95 & 1.11 & 1.14 & 1.38 & 1.72 \\
\hline Boston 20-Story & 3.11 & 1.14 & 0.680 & 0.485 & 0.371 & 1.96 & 1.23 & 1.37 & 1.66 & 2.02 \\
\hline Seattle 20-Story & 3.76 & 1.36 & 0.793 & 0.540 & 0.408 & 1.93 & 1.17 & 1.29 & 1.61 & 1.99 \\
\hline Los Angeles 20-Story & 3.81 & 1.32 & 0.766 & 0.544 & 0.414 & 1.93 & 1.18 & 1.14 & 1.66 & 2.04 \\
\hline
\end{tabular}

The seismic excitation for these generic frames is defined by a set of 20 largemagnitude-small-distance records (LMSR) listed in Medina and Krawinkler (2003). These ground motions were obtained from California earthquakes with magnitudes ranging from 6.6 to 6.9 recorded at distances of 13 to $30 \mathrm{~km}$.

The second set of structural systems will be referred to as "SAC" buildings. SAC commissioned three consulting firms to design 3-, 9-, and 20-story model buildings with symmetric plan according to the local code requirements of three cities: Los Angeles, Seattle, and Boston. Described in detail in Gupta and Krawinkler (1999), the structural systems of these model buildings consisted of perimeter steel moment-resisting frames (SMRF). The N-S perimeter frames of the 9- and 20-story buildings are the second set of systems analyzed in this paper. The modal vibration periods and damping ratios for these buildings are presented in Table 1.

For all three locations, sets of 20 ground motion records were assembled representing probabilities of exceedance of $2 \%$ and $10 \%$ in 50 years (return periods of 2,475 and 475 years, respectively) (Somerville et al. 1997). The $2 / 50$ set of records is used in the subsequent analyses.

\section{RESPONSE STATISTICS}

The dynamic response of each structural system to each of the 20 ground motions was determined by three procedures: nonlinear response history analysis (RHA), modal pushover analysis (MPA), and modified modal pushover analysis (MMPA). The "exact" peak value of the story drift, $\Delta$, determined by nonlinear RHA is denoted by $\Delta_{\mathrm{NL}-\mathrm{RHA}}$, and the approximate values from MPA and MMPA by $\Delta_{\mathrm{MPA}}$ and $\Delta_{\mathrm{MMPA}}$, respectively. From these data for each ground motion, two drift ratios are determined: $\Delta_{\mathrm{MPA}}^{*}=\Delta_{\mathrm{MPA}}$ $\div \Delta_{\mathrm{NL}-\mathrm{RHA}}$ and $\Delta_{\mathrm{MMPA}}^{*}=\Delta_{\mathrm{MMPA}} \div \Delta_{\mathrm{NL}-\mathrm{RHA}}$.

The median value, $\hat{x}$, defined as the geometric mean and the dispersion measure, $\delta$, of the $n$ observed values $x_{i}(i=1,2 \ldots n)$ of a random variable $x$ are defined as

$$
\hat{x}=\exp \left[\frac{\sum_{i=1}^{n} \ln x_{i}}{n}\right] ; \quad \delta=\left[\frac{\sum_{i=1}^{n}\left(\ln x_{i}-\ln \hat{x}\right)^{2}}{n-1}\right]^{1 / 2}
$$

The median value of the drift ratio provides an estimate of the bias in the results from an 
approximate procedure that underestimates the median response if the ratio is less than one and provides an overestimate if the ratio exceeds one. For small values, e.g., 0.3 or less, the above dispersion measure is close to the coefficient of variation. Subsequent sections will use the term "dispersion" when referring to this measure. Equations 1a and $\mathrm{b}$ are logical estimators for the median and dispersion, especially if the data are sampled from lognormal distribution (Benjamin and Cornell 1970), which is appropriate for earthquake response of structures.

In the case where one or more excitations caused collapse of the building or its first"mode" SDF system, the median and dispersion were estimated using a counting method. The 20 data values were sorted in ascending order, the median was estimated as the average of the $10^{\text {th }}$ and $11^{\text {th }}$ values starting from the lowest value; the $84^{\text {th }}$-percentile value as the $17^{\text {th }}$ value; and the dispersion $=\ln \left(84^{\text {th }}\right.$ percentile value $)-\ln$ (median value). Note that if more than three excitations caused collapse of the building or its first"mode" SDF system, the $84^{\text {th }}$-percentile value was unavailable and the dispersion was not calculated.

\section{MODAL PUSHOVER ANALYSIS PROCEDURES}

The equations of motion for a symmetric-plan multistory building subjected to earthquake ground acceleration $\ddot{u}_{g}(t)$ are the same as those for external forces, known as the effective earthquake forces (Chopra 2001, Section 9.4.1):

$$
\mathbf{p}_{\text {eff }}(t)=-\mathbf{m} 1 \ddot{u}_{g}(t)
$$

where $\mathbf{m}$ is the mass matrix and $\mathbf{1}$ is a vector with all elements equal to unity. Defined by $\mathbf{s} \equiv \mathbf{m} 1$, the spatial (height-wise) distribution of forces can be expanded into its modal components $\mathbf{s}_{n}$ :

$$
\mathbf{s}=\sum_{n=1}^{N} \mathbf{s}_{n} \quad \mathbf{s}_{n} \equiv \Gamma_{n} \mathbf{m} \phi_{n}
$$

where $\phi_{n}$ is the $n$ th-mode and $\Gamma_{n}=\phi_{n}^{T} \mathbf{m} \mathbf{1} / \phi_{n}^{T} \mathbf{m} \phi_{n}$

In the MPA procedure, the peak response of the building to $\mathbf{p}_{\mathrm{eff}, n}(t)=-\mathbf{s}_{n} \ddot{u}_{g}(t)$, the $n$ th-mode component of effective forces, is determined by a nonlinear static or pushover analysis. The peak "modal" demand $r_{n}$ is determined from pushover analysis for modal force distributions $\mathbf{s}_{n}^{*}=\mathbf{m} \phi_{n}$ at the peak roof displacement $u_{r n}$ associated with the $n$ th-"mode" inelastic SDF system. Gravity loads are included in each modal pushover analysis of the SAC buildings; these effects are not considered in analysis of generic frames. The peak "modal" demands due to the first few (typically 2 or 3 ) "modes" are then combined by the square-root-of-the-sum-of-squares rule to estimate the seismic demand on the buildings; details of this procedure are available in Goel and Chopra (2004).

Figures 1 and $2 \mathrm{a}$ and $\mathrm{b}$ show for SAC buildings pushover curves associated with the first, second, and third "modes," respectively, and identify the modal roof displacements due to each of the 20 ground motions and their median value; these roof displacements were determined by the MPA procedure (see Steps 5 and 6 in the summary of MPA pre- 

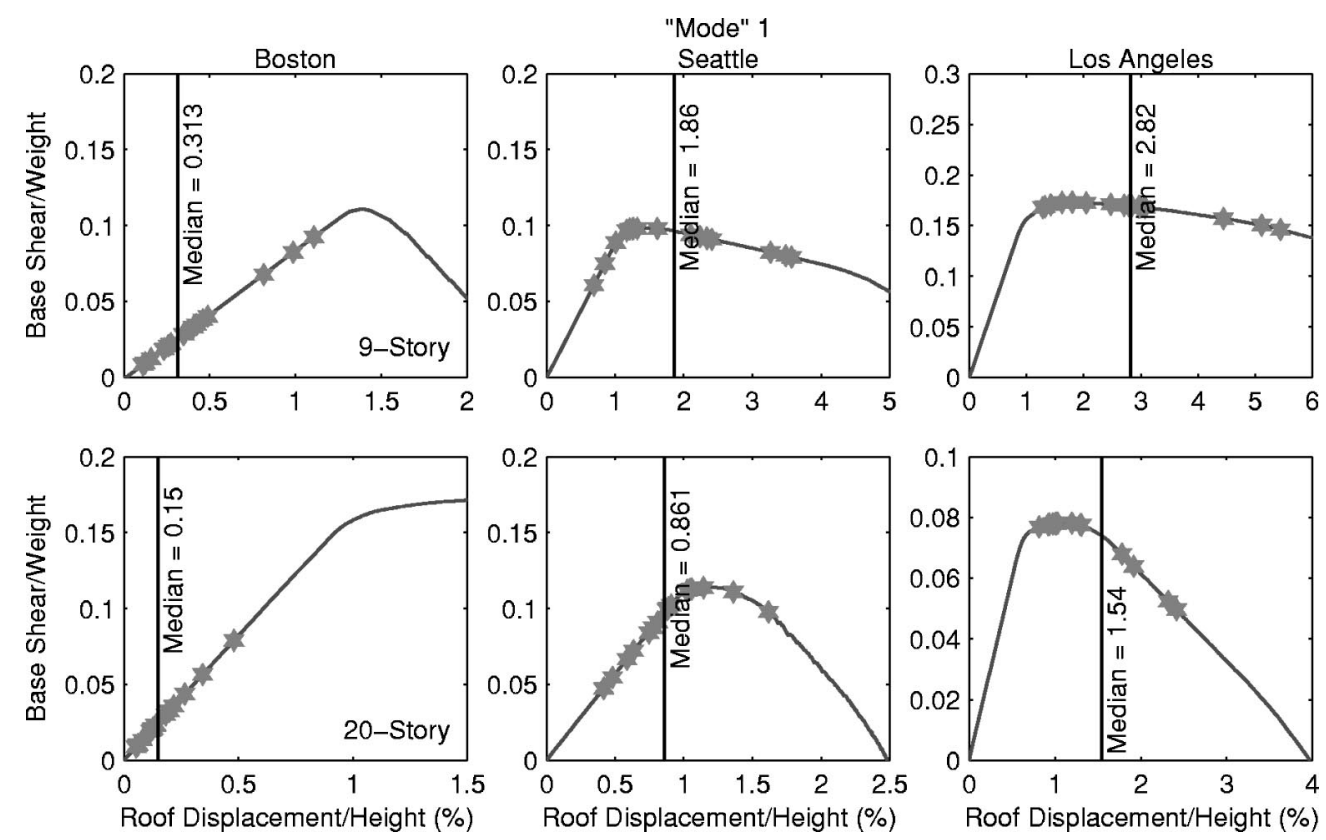

Figure 1. First-"mode" pushover curves for six SAC buildings; the target roof displacement due to each of 20 ground motions is identified and the median roof displacement is also noted.

sented later). Boston buildings remain elastic for all "modes" during all ground motions, and their median roof displacement is well below the yield displacement. Several ground motions drive the Seattle 9-story building well beyond the elastic limit in the first two "modes" but not in the third "mode." The median displacement is well beyond the yield displacement for the first "mode" but only slightly beyond for the second "mode." Several ground motions drive the Seattle 20 -story building well beyond the yield displacement in the first three "modes;" however, the median displacement exceeds the yield displacement significantly only for the second "mode." The very intense Los Angeles motions, which include several near-fault ground motions, drive the Los Angeles buildings well beyond the yield displacement in the first two modes; even the median displacement exceeds the yield displacement, although more so in the first mode than in the second. The overall impression is that some excitations deform the Seattle and Los Angeles buildings into the inelastic range in the first three "modes," but the median displacement in "modes" higher than the first is either close to or exceeds the yield displacement only by a modest amount.

These results suggest that for buildings subjected to intense excitation consideration of inelastic behavior of the structure is essential in the first "mode" pushover analysis, but may not be as important for the higher "modes." By ignoring inelastic behavior of the structures, the errors introduced in higher "mode" demands are expected to be less significant in estimating the total demand, which contains important contribution of the first "mode." 


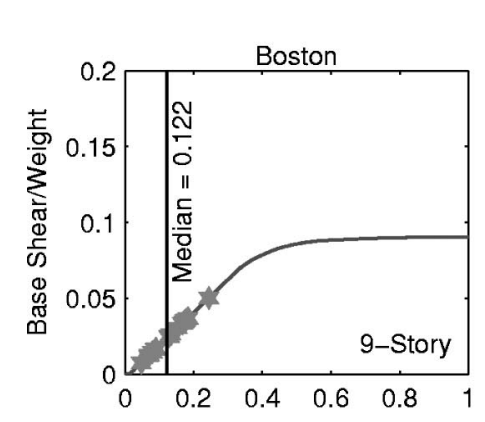

(a) "Mode" 2

Seattle
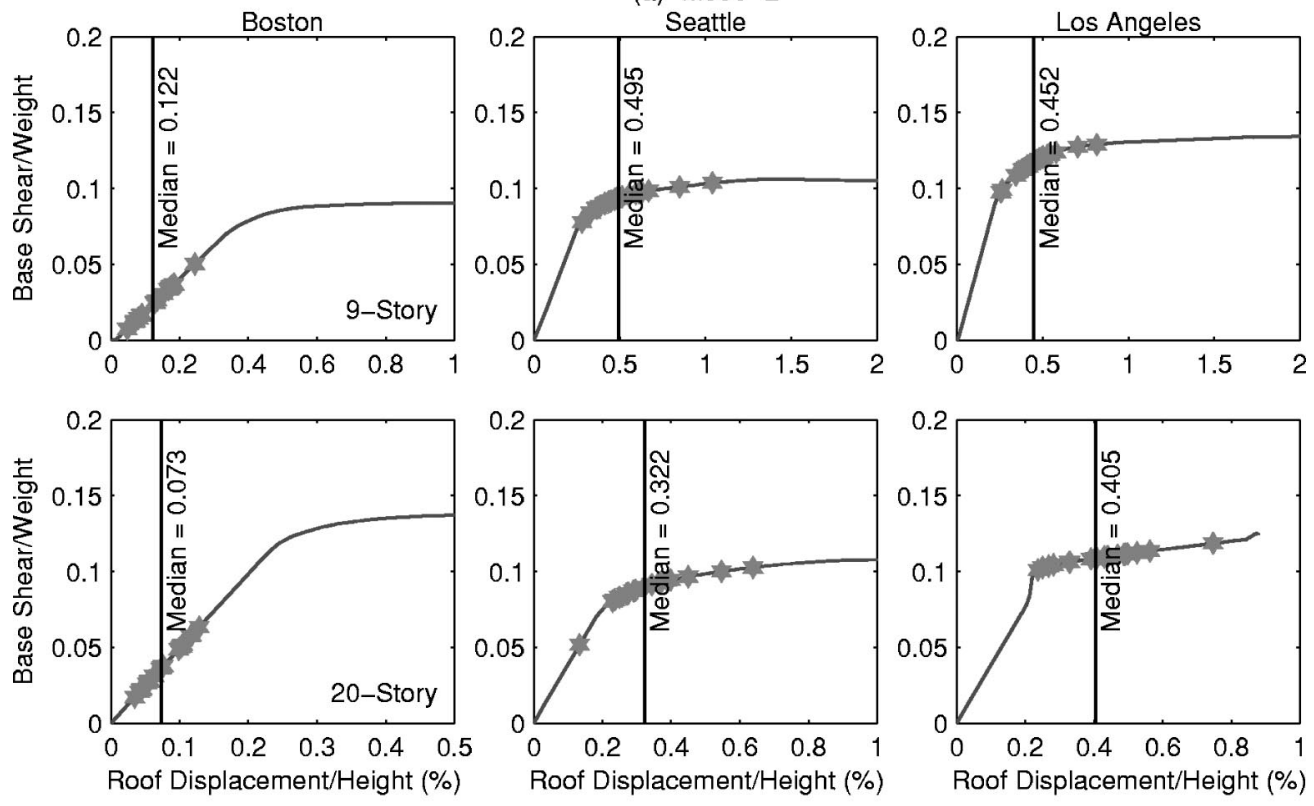

(b) "Mode" 3
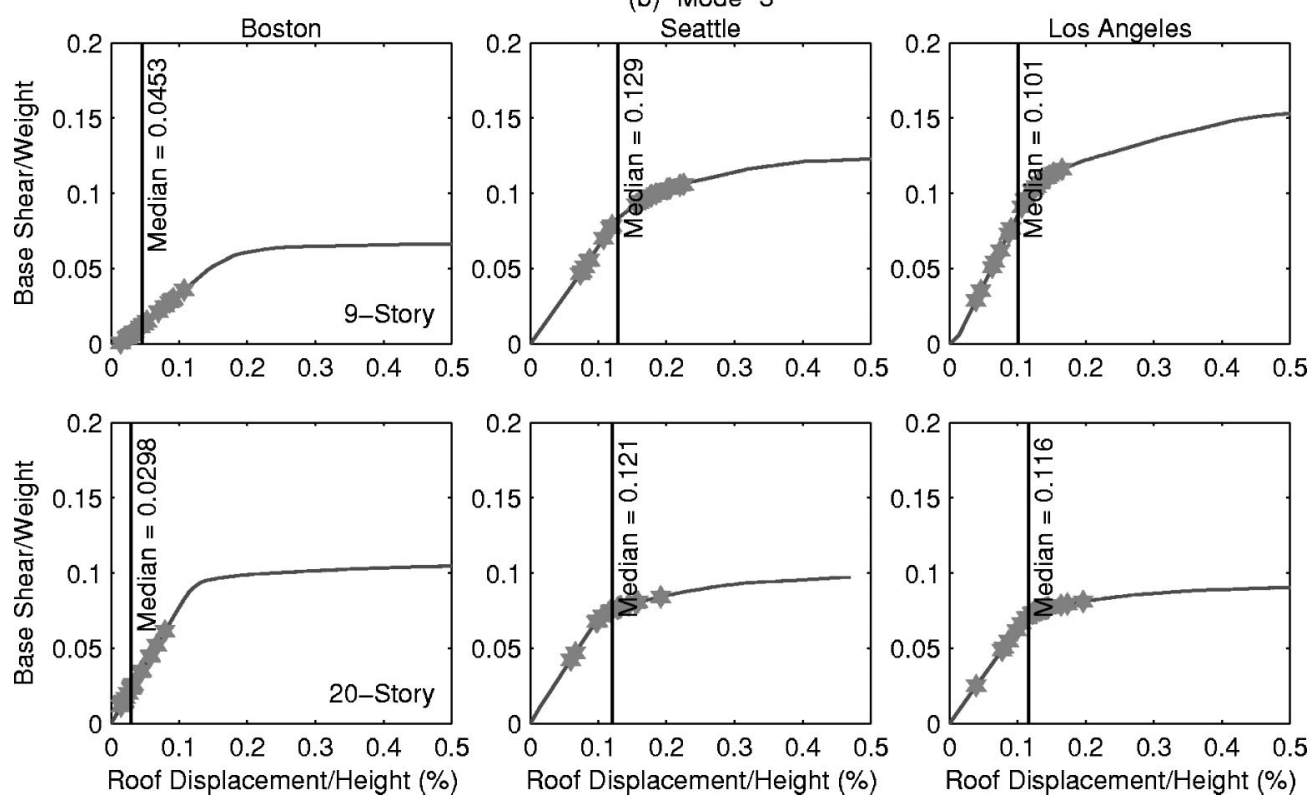

Figure 2. Second- and third-"mode" pushover curves for six SAC buildings; the target roof displacement due to each of 20 ground motions is identified and the median roof displacement is also noted. 
The pushover curves associated with the second and third "modes" of the two generic frames (6- and 12-story) and three design ductility factors $(\mu=1.5,4$, and 6$)$ are presented in Figure 3. These results are consistent with the pushover curves for SAC buildings (Figure 2); for low ductility factors $(\mu=1.5)$, the median displacement is either close to the yield value or exceeds the yield value only by a modest amount. As the design ductility factor and number of stories increase, a larger number of ground motions deform the generic frames well beyond the elastic limit, and the median displacement begins to increasingly exceed the yield value. Therefore, errors introduced in higher "mode" demands, by ignoring inelastic behavior of the structure, may be expected to increase with increasing ductility factor (or degree of inelastic action) and number of stories.

\section{MODIFIED MODAL PUSHOVER ANALYSIS PROCEDURE}

Thus it may be possible to obtain sufficiently accurate estimates of demand for some buildings by a Modified Modal Pushover Analysis (MMPA) procedure that differs from MPA only in one sense: The seismic demands due to higher "modes" are computed under the assumption that the system is elastic. This part of the analysis then becomes identical to classical modal analysis for linear systems (Chopra 2001, Chapter 13) and pushover analysis for higher "modes" is not needed.

Summarized below are a series of steps in the Modified Modal Pushover Analysis (MMPA) procedure to estimate the peak inelastic response of a multistory building with its plan symmetric about two orthogonal axes to earthquake ground motion along an axis of symmetry:

1. Compute the natural frequencies, $\omega_{n}$ and modes, $\phi_{n}$, for linearly elastic vibration of the building.

2. For the first mode (or fundamental mode), develop the base shear-roof displacement, $V_{b 1}-u_{r 1}$, pushover curve for force distribution, $\mathbf{s}_{1}^{*}=\mathbf{m} \phi_{1}$, where $\mathbf{m}$ is the mass matrix of the structure. Gravity loads, including those present on the interior (gravity) frames, are applied before the modal pushover analysis. The resulting P- $\Delta$ effects may lead to negative post-yielding stiffness in the pushover curve. Note the value of the lateral roof displacement due to gravity loads, $u_{r g}$.

3. Idealize the pushover curve as a bilinear curve. If the pushover curve exhibits negative post-yielding stiffness, the second stiffness (or post-yield stiffness) of the bilinear curve would be negative.

4. Convert the idealized $V_{b 1}-u_{r 1}$ pushover curve to the force-displacement, $F_{s 1} / L_{1}-D_{1}$, relation for the first-"mode" inelastic SDF system by utilizing $F_{s 1 y} / L_{1}=V_{b 1 y} / M_{1}^{*}$ and $D_{1 y}=u_{r 1 y} / \Gamma_{1} \phi_{r 1}$ in which $M_{1}^{*}$ is the effective modal mass, $\phi_{r 1}$ is the value of $\phi_{1}$ at the roof, and $\Gamma_{1}=\phi_{1}^{T} \mathbf{m} \mathbf{1} / \phi_{1}^{T} \mathbf{m} \phi_{1}$.

5. Compute the peak deformation $D_{1}$ of the first- "mode" inelastic single-degreeof-freedom (SDF) system defined by the force-deformation relation developed in Step 4 and damping ratio $\zeta_{1}$. For an SDF system with known $T_{1}$ and $\zeta_{1}, D_{1}$ 
(a) "Mode" 2
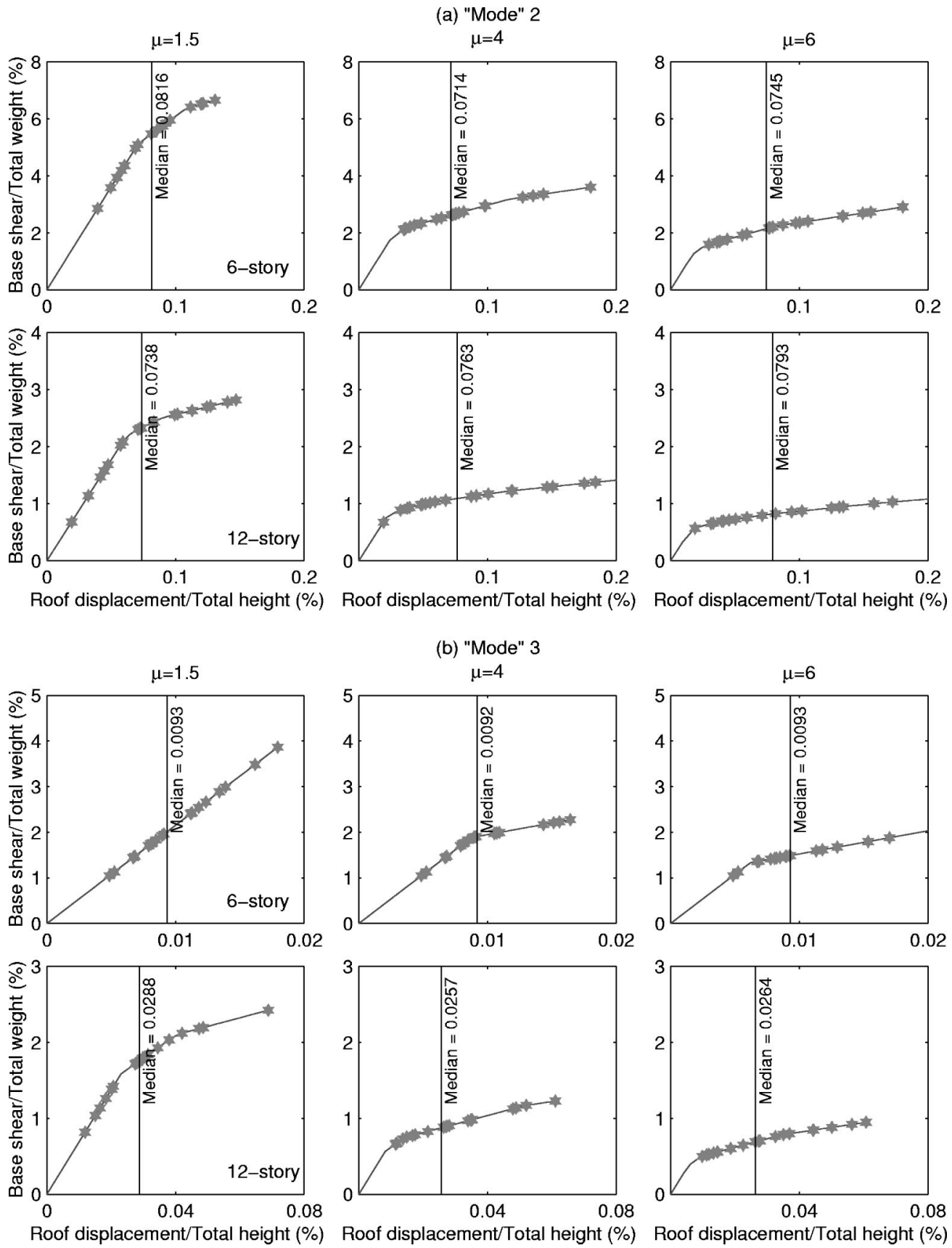

Figure 3. Second- and third-"mode" pushover curves of six generic frames (6- and 12-story, $\mu=1.5,4$, and 6); the target roof displacement due to each of 20 ground motions is identified and the median roof displacement is also noted. 
can be computed either by nonlinear RHA, from inelastic design spectrum, or by empirical equations for the ratio of deformations of inelastic and elastic systems (Chopra and Chintanapakdee 2004b).

6. Calculate peak roof displacement $u_{r 1}$ associated with the first-"mode" inelastic SDF system from $u_{r 1}=\Gamma_{1} \phi_{r 1} D_{1}$.

7. From the pushover database (Step 2), extract values of desired responses $r_{1+g}$ due to the combined effects of gravity and lateral loads at roof displacement equal to $u_{r 1}+u_{r g}$.

8. Compute the dynamic response due to first "mode:" $r_{1}=r_{1+g}-r_{g}$, where $r_{g}$ is the contribution of gravity loads alone.

9. Compute the dynamic response due to higher modes - higher than the fundamental mode - under the assumption that the system remains elastic. This part of the analysis is identical to computation of the response $r_{n}(n>1)$ for the $n$th mode from classical modal analysis of a linear MDF system with natural frequency, $\omega_{n}$, mode, $\phi_{n}$, and damping ratio $\zeta_{n}$. The deformation response, $D_{n}$, of the linear $n$ th-mode SDF system - with natural frequency $\omega_{n}$ and damping ratio $\zeta_{n}$-required in the analysis can be computed either by linear RHA or from elastic design spectrum. Repeat this analysis for as many modes as required for sufficient accuracy. For the 9-story buildings used in this investigation, three "modes" were found to be sufficient, whereas five "modes" were needed for the 20-story buildings. Note that pushover analysis for higher modes is not needed in this Step, thus reducing the computational effort.

Determine the total response (demand) by combining gravity response and the peak "modal" responses using the SRSS rule: $r \approx \max \left[r_{g} \pm\left(\sum_{n} r_{n}^{2}\right)^{1 / 2}\right]$, in which $r_{1}$ is from Step 8 and $r_{n}(n>1)$ from Step 9.

\section{HIGHER “MODE" CONTRIBUTIONS TO DEMAND}

The MPA and MMPA procedures were implemented for each of the six SAC buildings and for each of the 20 ground motions. The combined values of story drifts were computed for 9-story buildings including one, two, or three "modes" and for 20-story buildings including one, three, or five "modes." Figure 4 shows the median (over 20 excitations) values of story drift demands determined by the MPA procedure superimposed with the "exact" results of nonlinear response history analysis (RHA). Similar comparison of the MMPA and nonlinear RHA results are presented in Figure 5.

The first "mode" alone is inadequate in estimating story drifts (Figure 4). These demands are grossly underestimated in the upper stories of all buildings, and in the lower stories of Boston buildings. With sufficient number of "modes" included, two for 9-story buildings and three for 20 -story buildings, the height-wise distribution of story drifts estimated by MPA is generally similar to the trends obtained from nonlinear RHA. While discrepancies remain even after including higher mode contributions (see Goel and Chopra 2004), the estimates are now much superior to those based on first "mode" alone. 

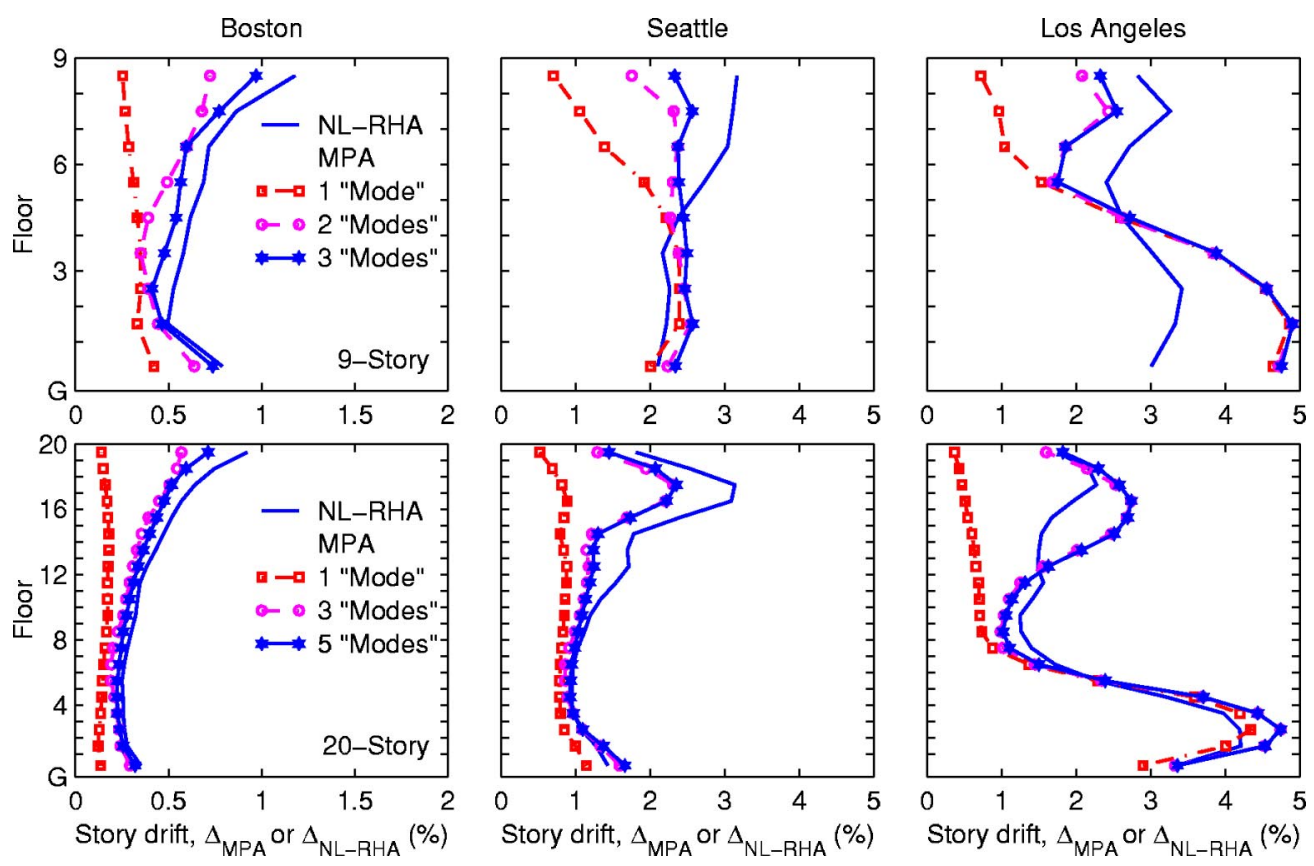

Figure 4. Median story drifts $\Delta_{\text {MPA }}$ determined by the MPA procedure with variable number of "modes" and nonlinear RHA for six SAC buildings.

Figure 5 demonstrates that such improvement is achieved even if the building is assumed to be elastic in estimating higher-"mode" contributions to demand; however, this additional approximation in the MMPA procedure can influence the estimate for total demand significantly, as is apparent by comparing Figures 4 and 5. This additional approximation has little influence in the case of Boston buildings because they remain essentially elastic (Figures 1 and 2); therefore, these buildings are not included in the subsequent results and discussion. In the case of the Seattle and Los Angeles buildings, however, it leads to significantly larger demands, because these building respond inelastically in some higher modes (Figure 2). The MMPA procedure provides better estimates (compared to the MPA procedure) for some cases (e.g., all stories of the Seattle 20-story building and upper stories of the Los Angeles 9-story building), but worse results in other cases (e.g., upper stories of the Los Angeles 20-story building and lower stories of the Seattle 9-story building); the benchmark for comparison is always the "exact" result from nonlinear RHA.

While both MPA and MMPA procedures give identical first-"mode" demand, they lead to different estimates of the response associated with higher "modes." Treating the building as elastic in the MMPA procedure leads to a different estimate for a higher"mode" response for two reasons. First, the demand due to force distribution $\mathbf{s}_{n}^{*}$ at a given roof displacement differs depending on whether the building is treated as elastic or inelastic. Second, the roof displacement, estimated from the deformation of an SDF sys- 

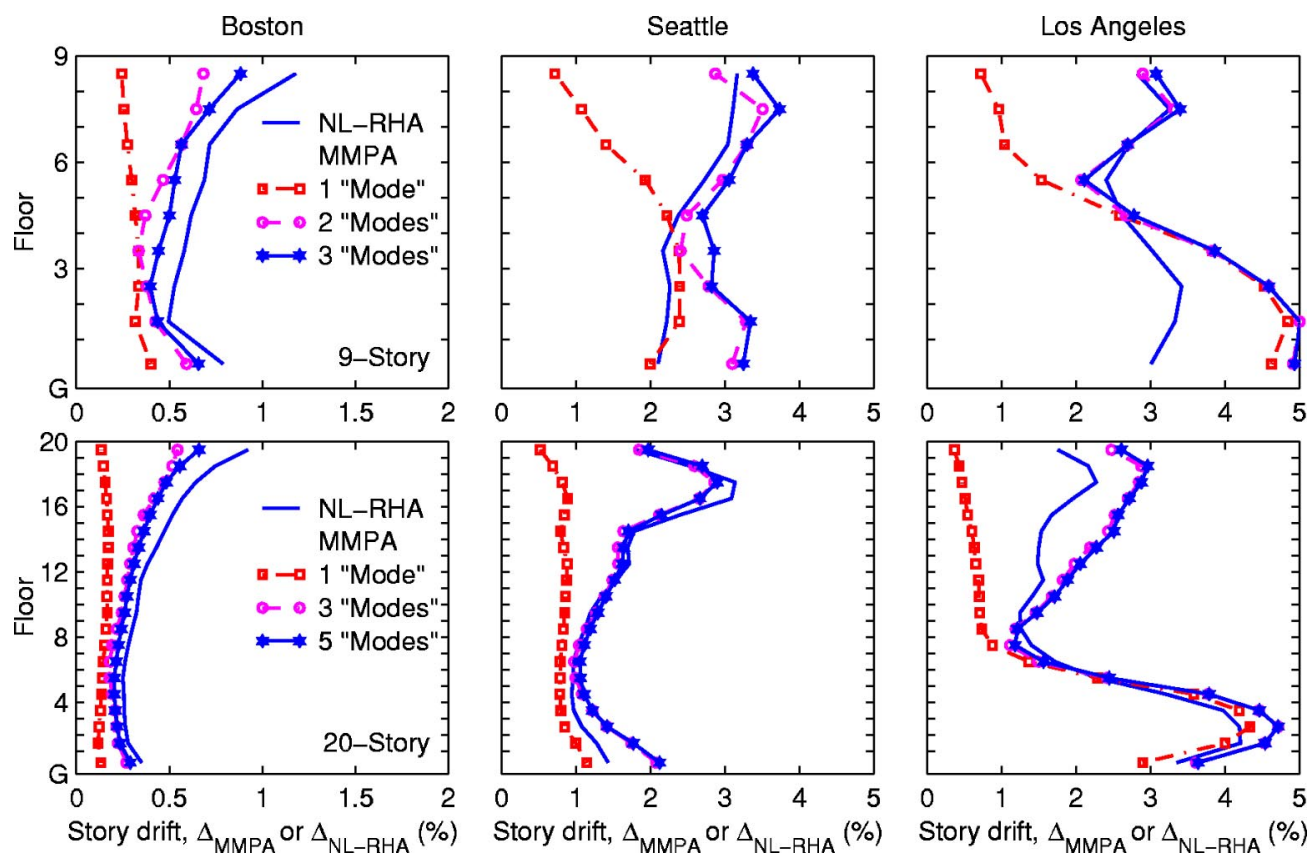

Figure 5. Median story drifts $\Delta_{\text {MMPA }}$ determined by the MMPA procedure with variable number of "modes" and nonlinear RHA for six SAC buildings.

tem, depends on whether the force-deformation curve for the SDF system is determined from the nonlinear pushover curve, as in MPA, or assumed to be linear, as in MMPA.

To examine the implication of the first source of discrepancy, the results of nonlinear static analysis for a higher-mode lateral-force distribution up to a selected roof displacement are compared with the results of linear analysis. Floor displacements and story drifts are presented in Figure 6 for a 12-story generic frame with design ductility factor $\mu=4$. For the same roof displacement, the displacements of all other floors of the system determined by nonlinear analysis are seen to be smaller because yielding of beams (identified by circles, sized to be proportional to plastic hinge rotations) is limited to the top two or three floors. Drifts in most stories are also smaller. Thus, for a given roof displacement, the higher-"mode" contributions to the seismic demand are overestimated in the MMPA procedure by ignoring inelastic behavior of the building. This observation applies to both the second and third modes.

To examine the implication of the second source of discrepancy, the roof displacement estimated (according to Steps 5 and 6 of the analysis procedure presented earlier) by using the inelastic SDF system for the second and third "modes" is plotted against that from the corresponding elastic SDF system for each of the 20 ground motions and the median values of roof displacement from the two procedures are noted. Figure 7 shows such results for six of the 30 generic frames. The median roof displacement is overestimated by up to $21 \%$ when the building is assumed to be elastic. This is consis- 
(a) Floor displacements due to $\mathbf{s}^{*}$

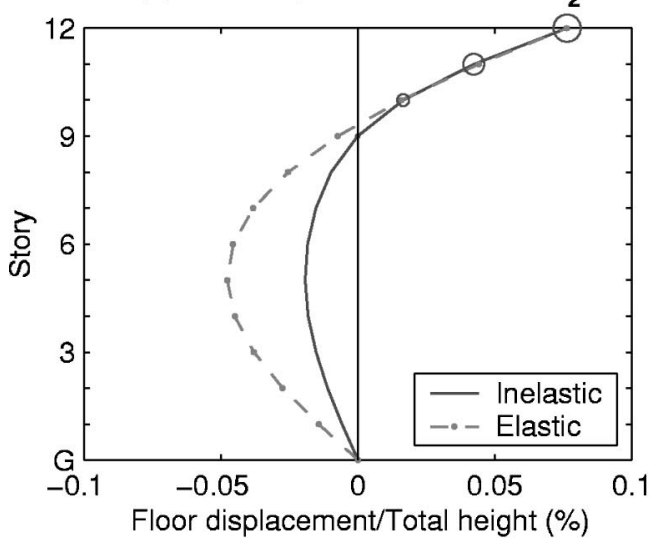

(c) Story drift due to $\mathbf{s}^{*}$

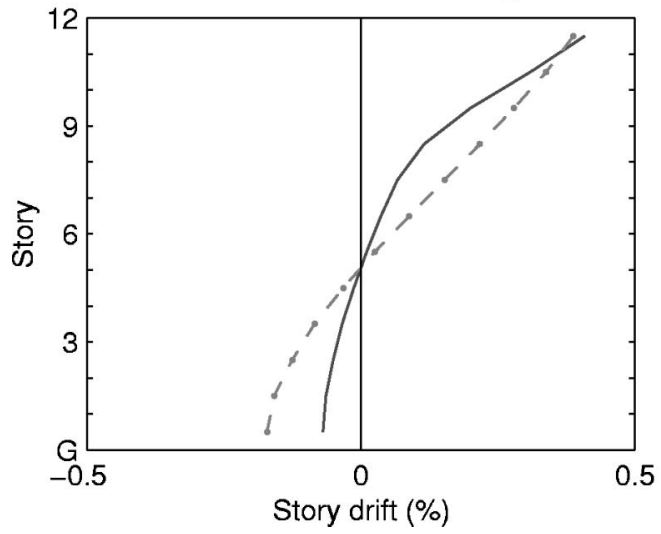

(b) Floor displacements due to $\mathbf{s}^{*}{ }_{3}$

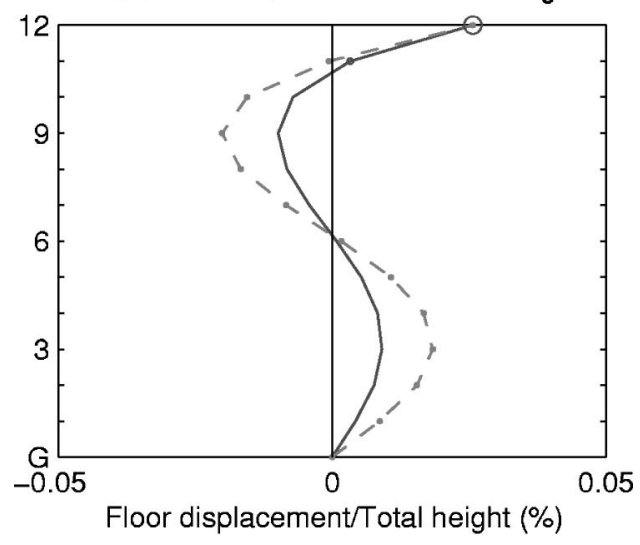

(d) Story drift due to $\mathbf{S}^{*}$

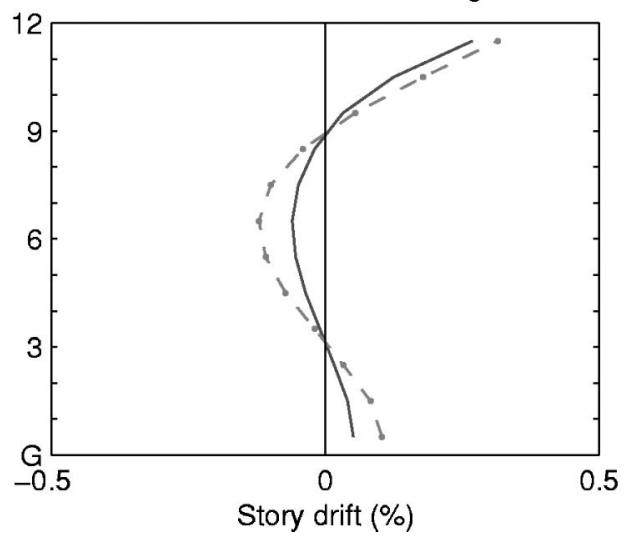

Figure 6. Floor displacements and story drifts of a 12-story generic frame with $\mu=4$ from inelastic and elastic pushover analyses up to the same roof displacement due to second- and thirdmode force distributions, $\mathbf{s}_{2}^{*}$ and $\mathbf{s}_{3}^{*}$.

tent with the data on inelastic deformation ratios for SDF systems with 5\% damping and periods in the velocity-sensitive region or lower-end of the displacement-sensitive region of the median response spectrum (Chopra and Chintanapakdee 2004b). This period range includes the periods of the second and third "modes" of most of these generic frames and their modal damping ratios were chosen close to $5 \%$.

Figure 8 shows similar results for the SAC buildings determined from inelastic and elastic SDF systems associated with their second and third "modes." Observe that the peak deformation of the elastic system due to a few excitations is more than twice that of the inelastic system. The median deformation of the elastic system is much larger than that of the inelastic system for both Seattle buildings and the Los Angeles 9-story building and is slightly larger in case of the Los Angeles 20 -story building. This is surprising because the second-mode periods of these buildings are in the velocity-sensitive 


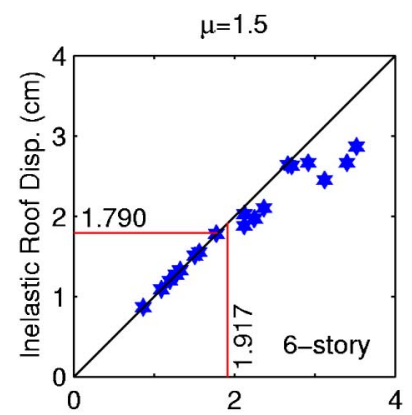

(a) "Mode" 2
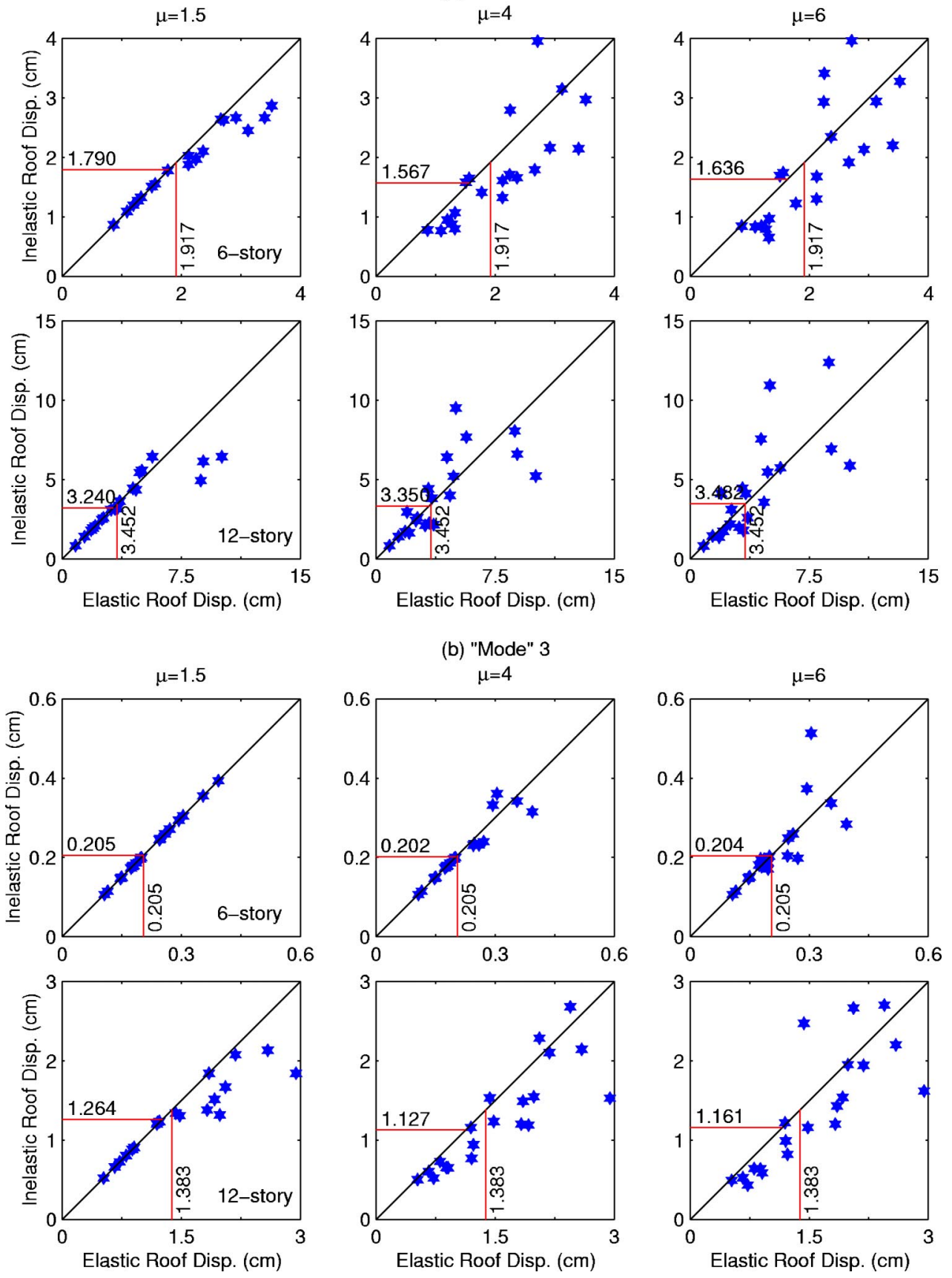

Figure 7. Inelastic versus elastic roof displacements associated with the second and third "modes" of 6- and 12-story generic frames with $\mu=1.5,4$, and 6; median values are noted. 

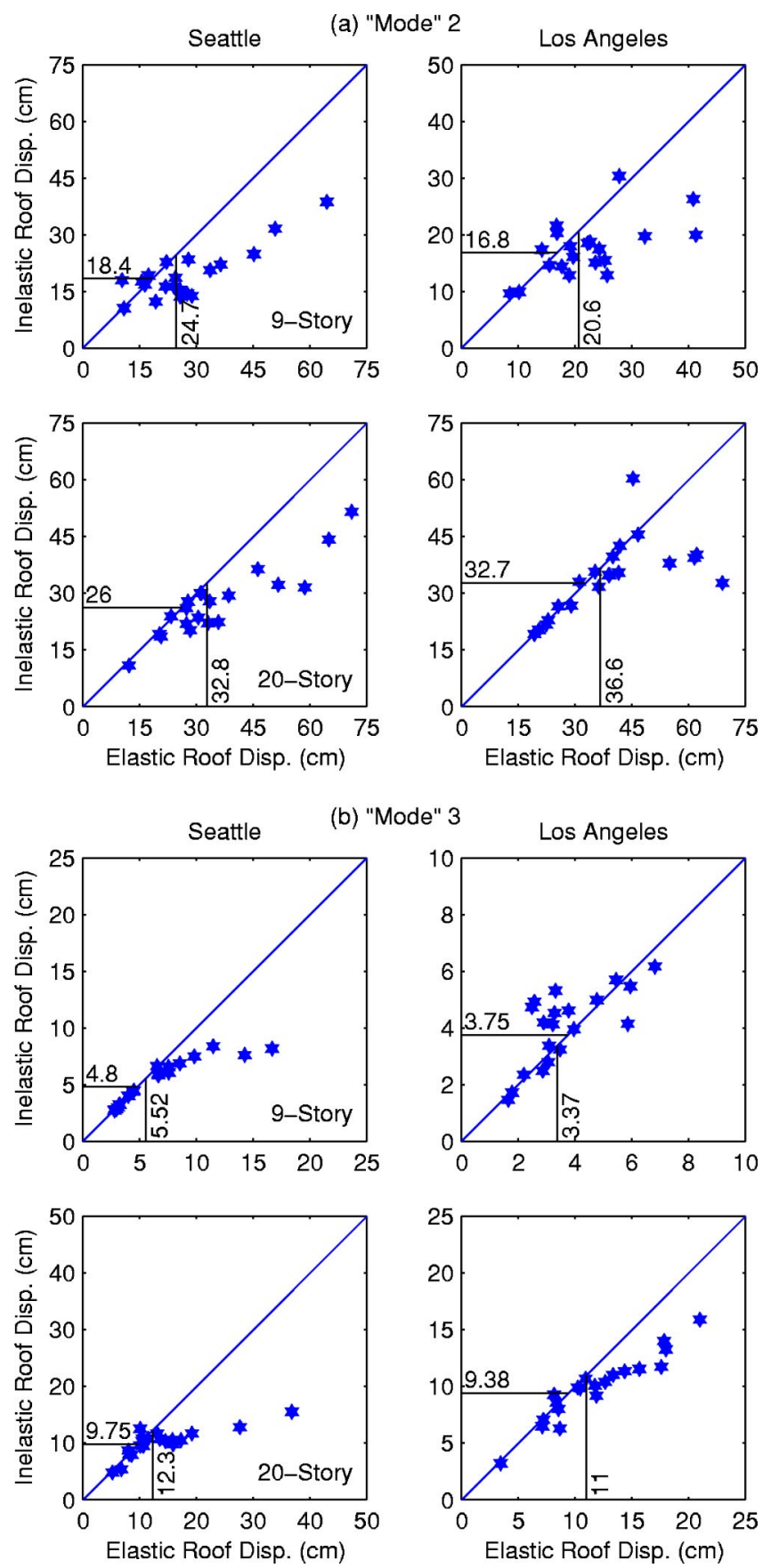

Figure 8. Inelastic versus elastic roof displacements associated with second and third "modes" of four SAC buildings; median values are noted. 

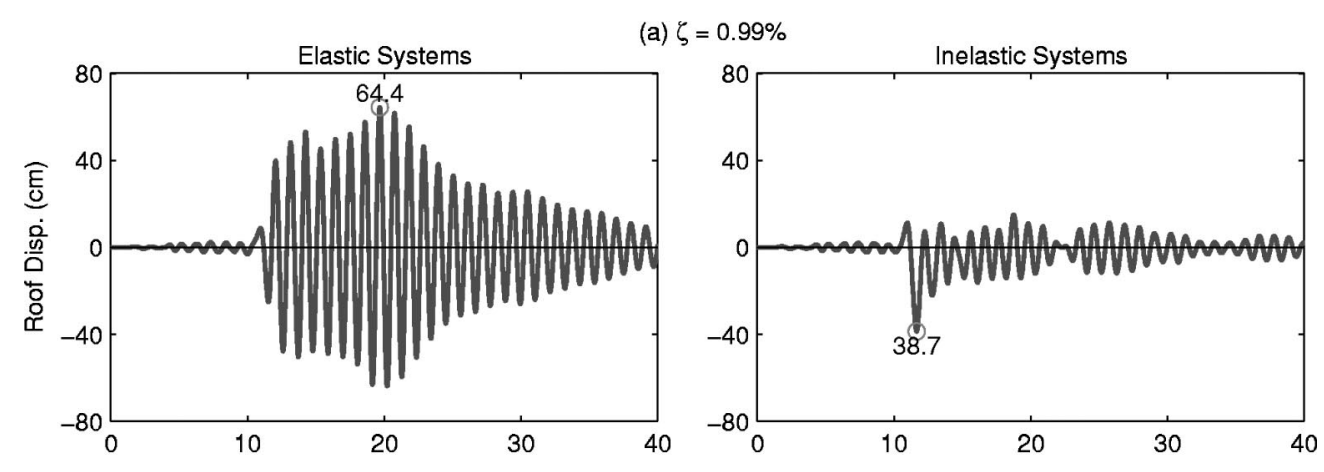

(b) $\zeta=5 \%$
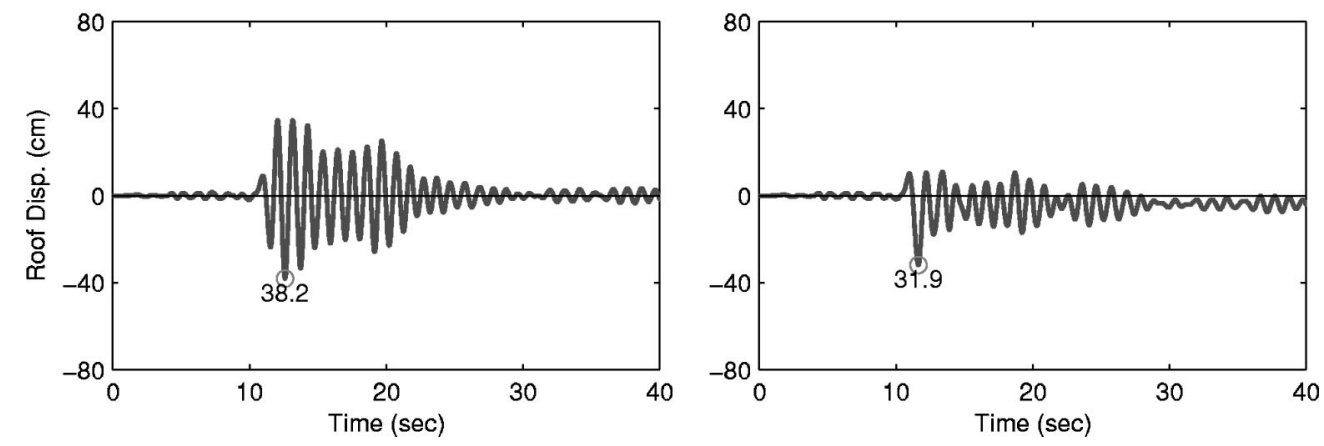

Figure 9. Time-variation of roof displacement for Seattle 9-story building obtained from elastic and inelastic analysis of the second-"mode" SDF system for earthquake record SE36 for two damping values: (a) $\zeta=0.99 \%$ and (b) $\zeta=5 \%$.

region of the median response spectrum where, according to prevailing view, the deformation of the elastic system is expected to be about the same as that of the inelastic system.

Starting with a classic paper (Veletsos and Newmark 1960), this long-held view is based largely on computed deformations of inelastic and elastic SDF systems with moderate damping, typically 5\% (e.g., Chopra and Chintanapakdee 2004b). To investigate this apparent anomaly, Figures $9 \mathrm{a}$ and $9 \mathrm{~b}$ compare the roof displacement of the Seattle 9-story building associated with its second "mode" due to one ground motion determined by analyses of inelastic and elastic SDF systems; the damping ratio for this mode of this SAC building is very low, only about $1 \%$ (Table 1 ). The peak deformation of the elastic system is 1.66 times of the inelastic system; however, if the damping ratio is arbitrarily increased to $5 \%$, the peak deformations of the two systems are much closer (Figure 9b).

\section{COMPARATIVE EVALUATION OF ANALYSIS PROCEDURES}

The results presented in the preceding section indicate that the two sources of discrepancy in the MMPA procedure will combine towards overestimating higher-"mode" 
contributions to seismic demands if the building is analyzed assuming elastic behavior. This expectation is verified next by examining response of generic frames as well as SAC buildings.

\section{GENERIC FRAMES}

The bias in the MPA and MMPA procedures for 30 generic frames is compared in Figure 10, which plots the median story-drift ratio estimated by the two procedures. The story drifts are always larger when the contributions of higher modes are computed by linear analysis. Modified modal pushover analysis provides a less biased (or more accurate) estimate of seismic demand for those frames where MPA underestimates demand (relative to nonlinear RHA), but a more biased (or less accurate) estimate for frames where MPA already overestimated the demand (e.g., upper stories of 15 and 18-story frames with $\mu=4$ and 6). As noted previously, the difference between estimates by MPA and MMPA procedures increases with increasing design ductility factor $\mu$, implying more inelastic action in higher "modes" (Figure 3), and with increasing number of stories, $N$ implying more significant response contributions from higher modes. This increased difference is especially noticeable in the upper stories of frames where higher"mode" contributions are especially significant, and their overestimation in the MMPA procedure is more consequential in the total demand. For frames with 9 or fewer stories and design ductility $\mu=2$ or less, the MPA and MMPA procedures are similarly biased (or accurate); however, the bias of the MMPA procedure exceeds $25 \%$ for 15 and 18 story frames with $\mu=4$ and 6 .

Figure 11 presents the dispersion of the drift ratio $\Delta_{\mathrm{MPA}}^{*}$ and $\Delta_{\mathrm{MMPA}}^{*}$ plotted over the height of all the 30 generic frames. The similarity between the two sets of dispersion data suggests that ignoring inelastic behavior of the building in estimating higher"mode" contributions to seismic demands does not lead to any significant increase in dispersion; surprisingly, the dispersion is reduced for several frames.

\section{SAC BUILDINGS}

The expectation of the MMPA procedure overestimating higher-"mode" contributions to seismic demands if the building is analyzed assuming elastic behavior is also confirmed for SAC buildings. Figure 12 shows that the median of the story drift ratio estimated by the MMPA procedure is almost always larger than the MPA value, as observed for generic frames. If the MPA estimate is biased towards underestimating the demand, the MMPA procedure may improve the estimate (e.g., upper stories of the Seattle 20-story building). However, if the MPA estimate is biased towards overestimating the demand, the MMPA procedure worsens the estimate (e.g., upper stories of the Los Angeles 20-story building). Note that ignoring inelastic behavior in estimating higher "mode" contributions to seismic demand increases the demand estimate considerably, much more than in the case of generic frames (Figure 10). This unexpectedly large increase in the demand estimate is primarily due to the much larger roof displacement pre-

dicted by elastic "modal" SDF system compared to the inelastic "modal" SDF system for very lightly damped modes, as demonstrated earlier in Figure 9. 


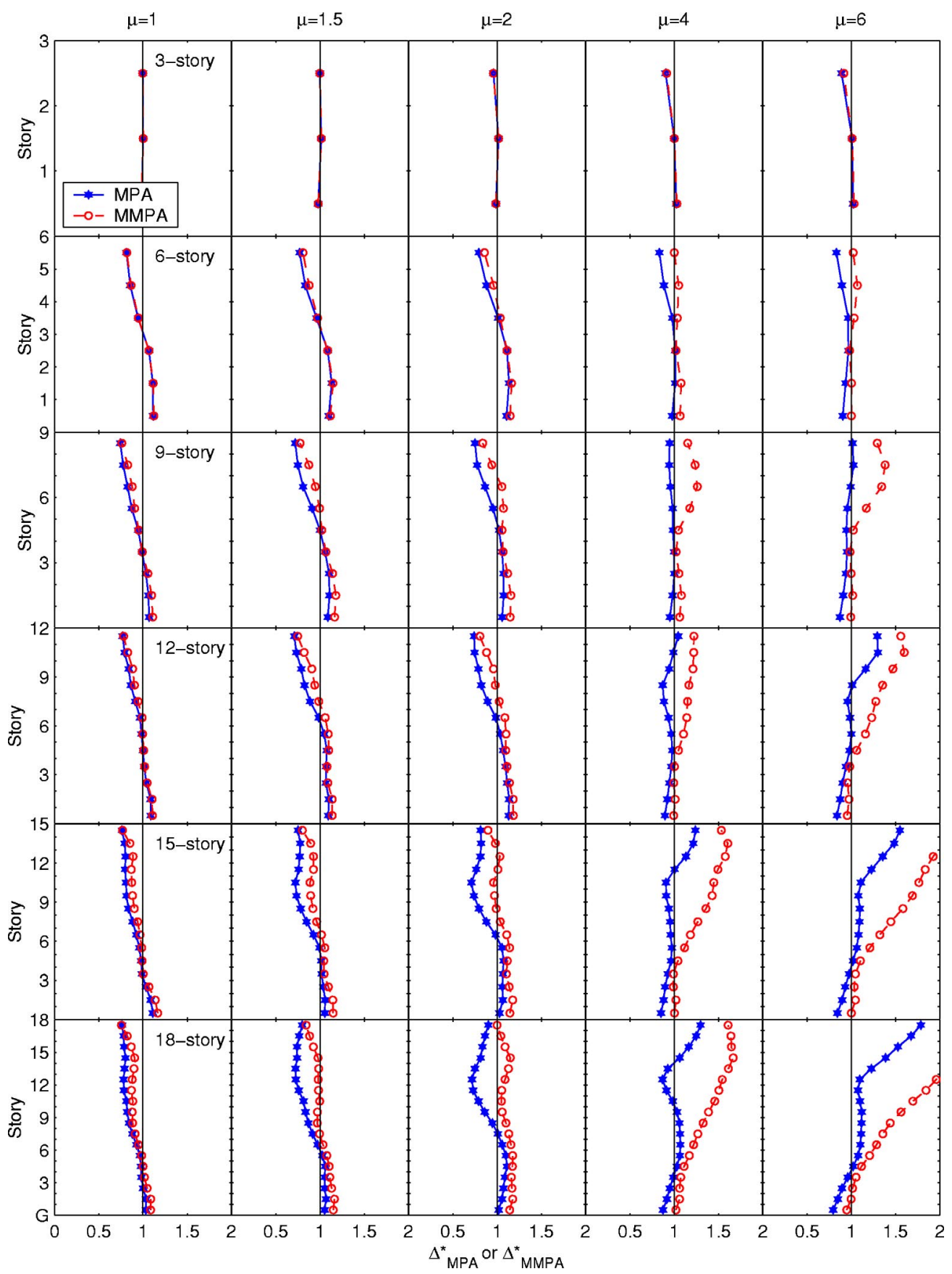

Figure 10. Median story-drift ratios $\Delta_{\mathrm{MPA}}^{*}$ and $\Delta_{\mathrm{MMPA}}^{*}$ for 3, 6, 9, 12, 15, and 18-story generic frames (with $T_{1}=T_{U}$ ), each designed for $\mu=1,1.5,2,4$, and 6 . 


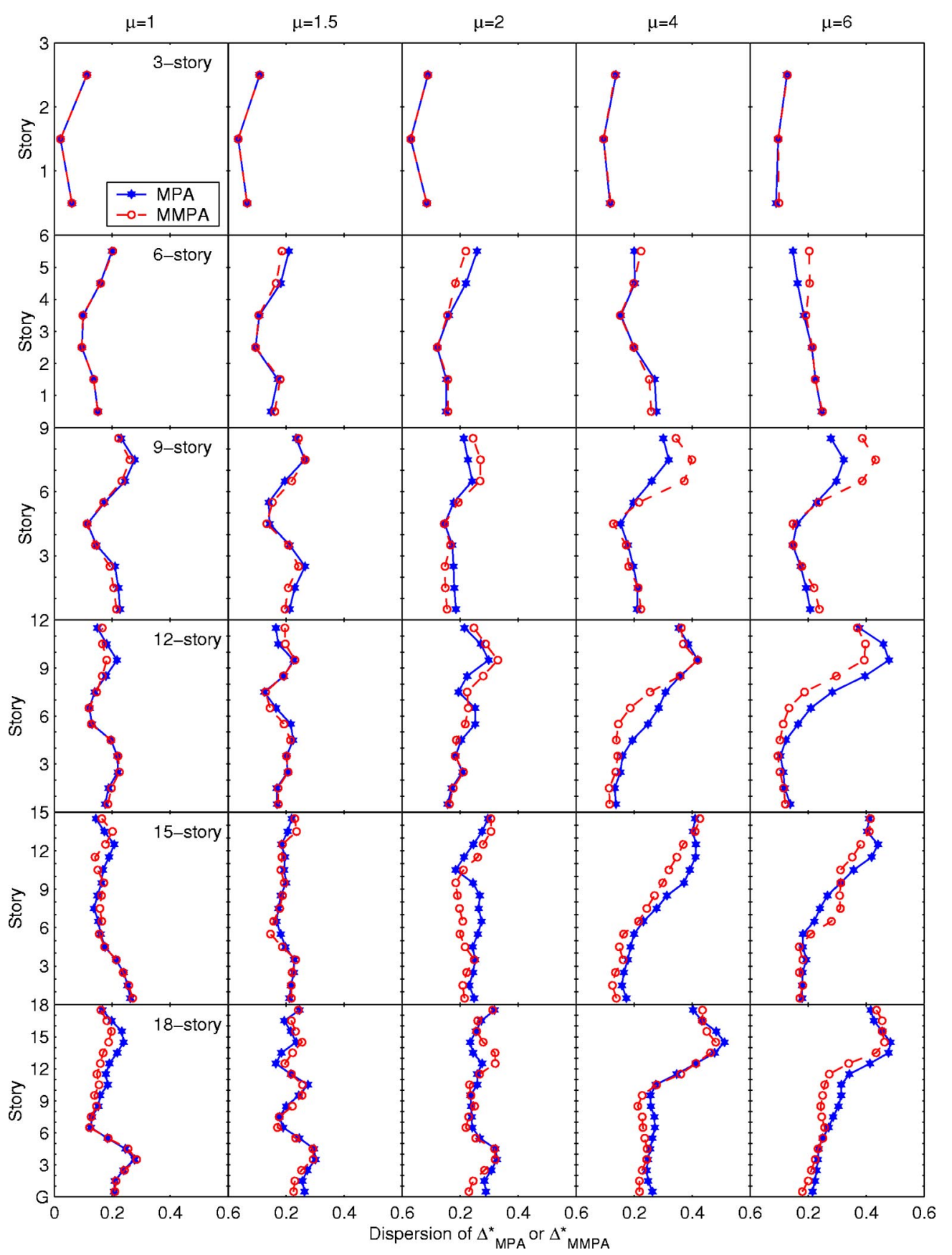

Figure 11. Dispersion of story-drift ratios $\Delta_{\mathrm{MPA}}^{*}$ and $\Delta_{\mathrm{MMPA}}^{*}$ for 3, 6, 9, 12, 15, and 18-story generic frames (with $T_{1}=T_{U}$ ), each designed for $\mu=1,1.5,2,4$, and 6 . 

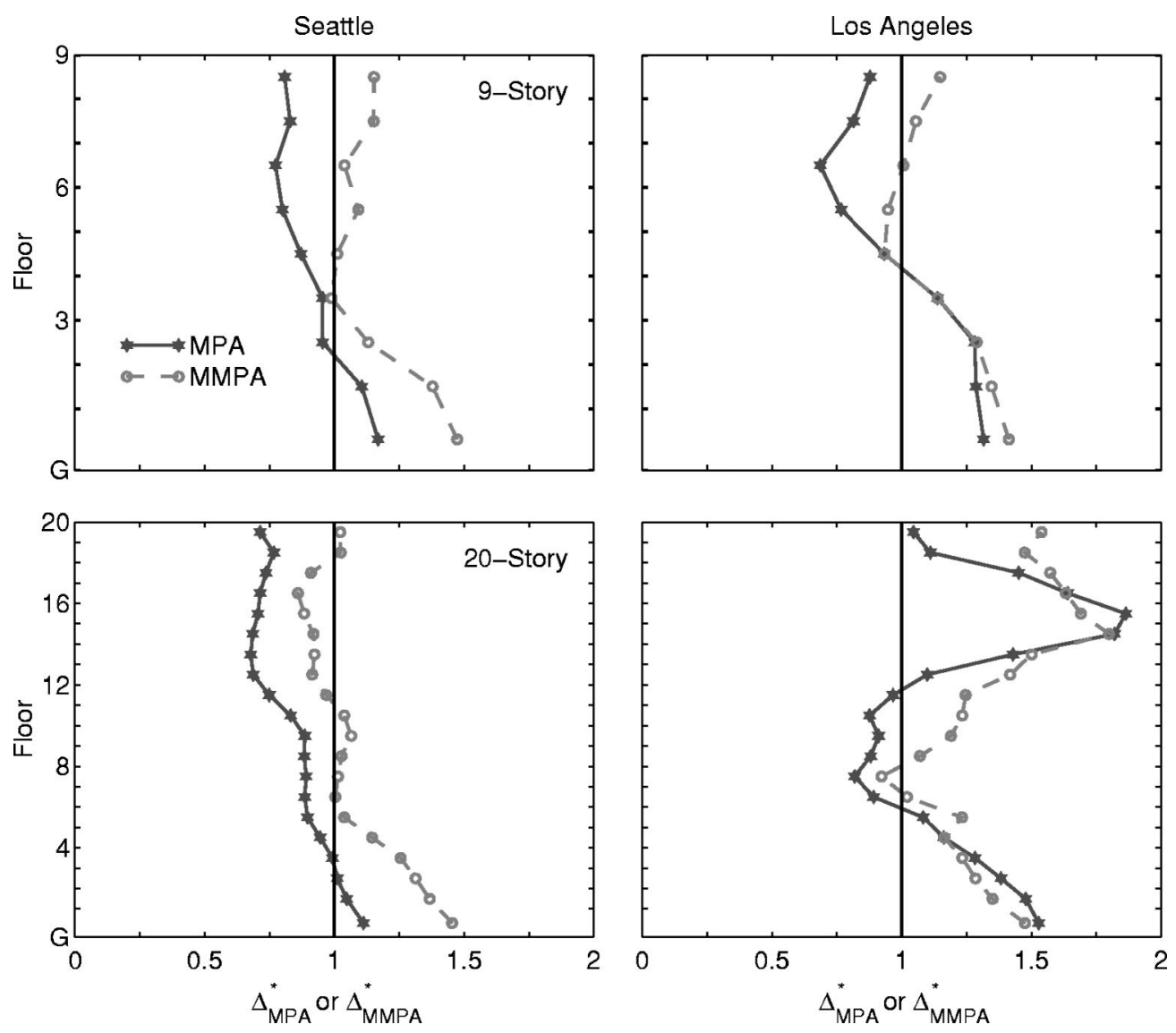

Figure 12. Median story-drift ratios $\Delta_{\mathrm{MPA}}^{*}$ and $\Delta_{\mathrm{MMPA}}^{*}$ for four SAC buildings.

Figure 13 presents the dispersion of the drift ratio $\Delta_{\mathrm{MPA}}^{*}$ and $\Delta_{\mathrm{MMPA}}^{*}$ plotted over the height of the SAC buildings. These results show that ignoring inelastic behavior of the building in estimating higher-"mode" contributions to seismic demands increases dispersion significantly in upper stories of the Los Angeles 9-story building and all except the lower few stories of the Seattle 20-story building; surprisingly, the dispersion is reduced at some locations in few buildings, e.g., lower half of the Seattle 9-story building. Note that dispersion could not be calculated for the Los Angeles 20-story building because more than three excitations caused collapse of the first-"mode" SDF system.

Pushover analysis procedures, such as MPA and MMPA, are intended for use in conjunction with a smooth design spectrum that defines the seismic hazard. For this reason, this paper focused on the bias and dispersion in these approximate procedures. If they are used to estimate seismic demands due to an individual ground motion, which we do not recommend, the error in the approximate results may be much larger than might be suggested by the results presented in this paper. 

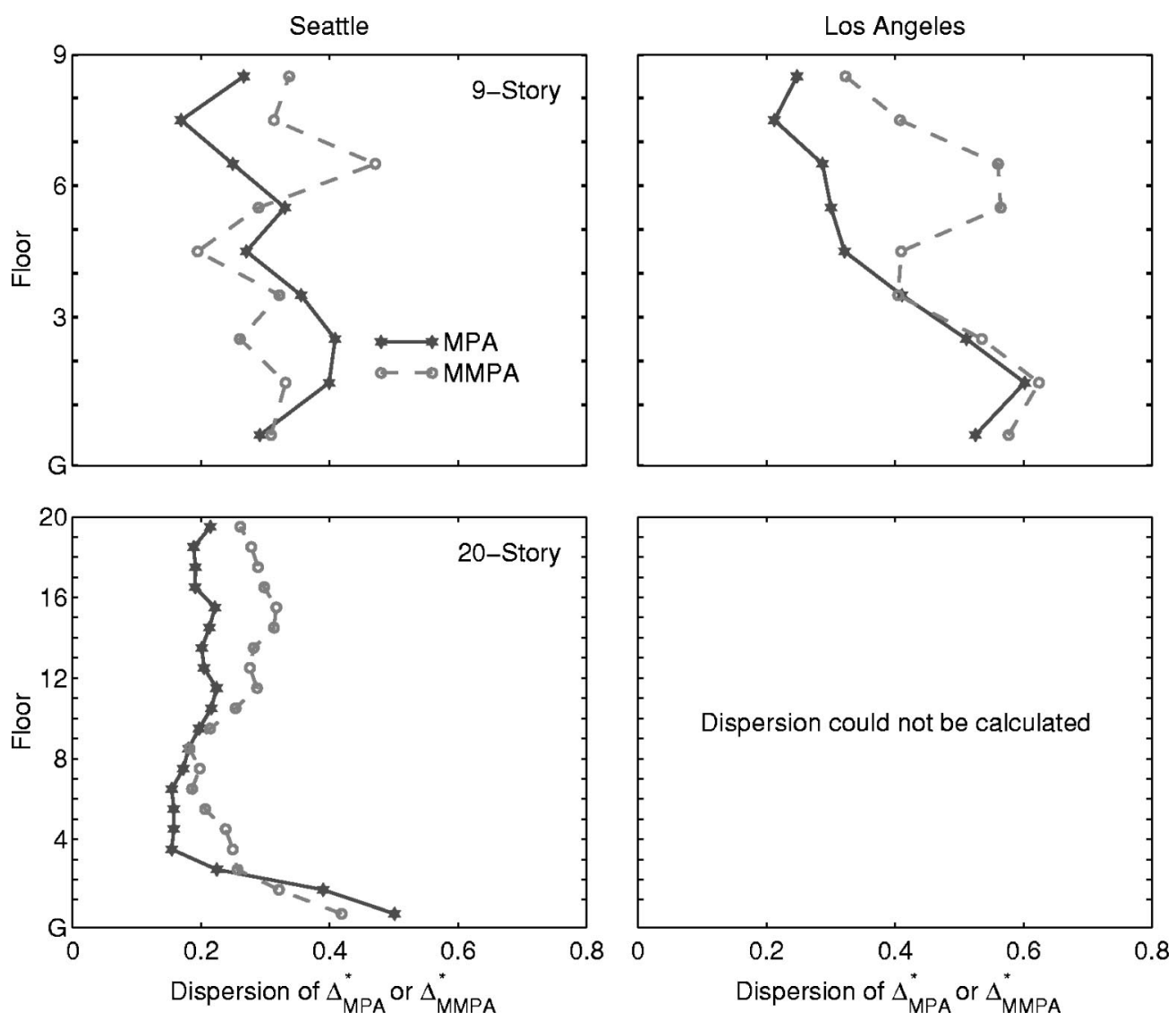

Figure 13. Dispersion of story-drift ratios $\Delta_{\mathrm{MPA}}^{*}$ and $\Delta_{\mathrm{MMPA}}^{*}$ for four SAC buildings; dispersion could not be calculated for the Los Angeles 20-story building because more than three excitations caused collapse of the first-"mode" SDF system.

\section{CONCLUSIONS}

The Modified Modal Pushover Analysis (MMPA) procedure, where the building is treated as linearly elastic in estimating the higher-"mode" contributions to seismic demands, is a viable alternative to the MPA procedure. This additional approximation in the MMPA procedure increases the demand estimate for SAC buildings and the 108 generic frames analyzed (results for only 30 frames were presented here).

The MMPA procedure provides a larger estimate of demand, although it is not necessarily more accurate than the MPA procedure. The MMPA generally provided a less biased (or more accurate) estimate of seismic demand for those structures where MPA underestimates demand (relative to nonlinear RHA), but a more biased (or less accurate) estimate for cases where MPA already overestimates the demand. 
The MMPA procedure is an attractive alternative for practical application because it leads to a larger estimate of seismic demand, thus reducing the unconservatism (relative to nonlinear RHA) of MPA results in some cases and increasing their conservatism in others. While this increase in demand is modest and acceptable for systems with moderate damping, around $5 \%$, it is unacceptably large for lightly damped systems, e.g., SAC buildings. Thus the MMPA procedure is not recommended for such systems.

Ignoring inelastic behavior of the building in MMPA in estimating higher-"mode" contributions to seismic demands does not lead to any significant increase in the dispersion of the error.

This paper has focused on estimation of deformation demands, in particular story drifts, which are of primary interest in performance-based engineering. Accuracy of force demands estimated by the MPA and MMPA procedures has, so far, not been evaluated, but such MPA-related work is in progress.

\section{ACKNOWLEDGMENTS}

This research investigation is funded by the National Science Foundation under Grant CMS-9812531, a part of the U.S. Japan Cooperative Research in Urban Earthquake Disaster Mitigation. The research reported in this paper was prompted by a question from the audience after the first author's presentation at the TUSNCEE in Boston, July 2002. The ATC-5S project added urgency to this work.

\section{REFERENCES}

American Society of Civil Engineers (ASCE), 2001. Prestandard and Commentary for the Seismic Rehabilitation of Buildings, prepared for the SAC Joint Venture, published by the Federal Emergency Management Agency, FEMA-356, Washington, D.C.

Benjamin, J. R., and Cornell, C. A., 1970. Probability, Statistics, and Decision for Civil Engineers, McGraw-Hill, New York, 684 pp.

Bracci, J. M., Kunnath, S. K., and Reinhorn, A. M., 1997. Seismic performance and retrofit evaluation for reinforced concrete structures, J. Struct. Eng., ASCE, 123 (1), 3-10.

Chintanapakdee, C., and Chopra, A. K., 2002. Evaluation of modal pushover analysis using vertically "regular" and irregular generic frames, Report No. UCB/EERC 2003-03, Earthquake Engineering Research Center, University of California, Berkeley, CA.

Chopra, A. K., 2001. Dynamics of Structures: Theory and Applications to Earthquake Engineering, 2nd ed., Prentice-Hall, Englewood Cliffs, NJ, 844 pp.

Chopra, A. K., and Goel, R. K., 2002. Modal pushover analysis procedure for estimating seismic demands for buildings, Earthquake Eng. Struct. Dyn. 31 (3), 561-582.

Chopra, A. K., and Chintanapakdee, C., 2004a. Evaluation of modal and FEMA pushover analyses: Vertically "regular" and irregular generic frames, Earthquake Spectra 20 (1), 255271.

Chopra, A. K., and Chintanapakdee, C., 2004b. Inelastic deformation ratios for design and evaluation of structures: SDF bilinear systems, J. Struct. Eng., ASCE, 130 (9), 1-11.

Eberhard, M., and Sozen, M. A., 1993. Behavior-based method to determine design shear in earthquake-resistant walls, J. Struct. Eng., ASCE, 119 (2), 619-640. 
Goel, R. K., and Chopra, A. K., 1997. Period formulas for moment-resisting frame buildings, $J$. Struct. Eng., ASCE, 123 (11), 1454-1461.

Goel, R. K., and Chopra, A. K., 2004. Evaluation of modal and FEMA pushover analysis: SAC buildings, Earthquake Spectra 20 (1), 225-254.

Gupta, A., and Krawinkler, H., 1999. Seismic demands for performance evaluation of steel moment resisting frame structures (SAC Task 5.4.3), Report No. 132, John A. Blume Earthquake Engineering Center, Stanford University, Stanford, CA.

Gupta, B., and Kunnath, S. K., 2000. Adaptive spectra-based pushover procedure for seismic evaluation of structures, Earthquake Spectra 16 (2), 367-392.

International Code Council (ICC), 2000. 2000 International Building Code, Falls Church, VA.

Kunnath, S. K., and Gupta, B., 2000, Validity of deformation demand estimates using nonlinear static procedures, Proceedings of U.S.-Japan Workshop on Performance-Based Earthquake Engineering Methodology for Reinforced Concrete Building Structures, Sapporo, Hokkaido, Japan, pp. 117-128.

Matsumori, T., Otani, S., Shiohara, H., and Kabeyasawa, T., 2000, Earthquake member deformation demands on reinforced concrete frame structures, Proceedings of U.S.-Japan Workshop on Performance-Based Earthquake Engineering Methodology for Reinforced Concrete Building Structures, Maui, HI, pp. 79-94.

Medina, R. A., and Krawinkler, H., 2003. Seismic demands for non-deteriorating structures and their dependence on ground motions, John A. Blume Earthquake Engineering Center, Report No. 144, Department of Civil and Environmental Engineering, Stanford University, Stanford, CA.

Paret, T. F., Sasaki, K. K., Eilbeck, D. H., and Freeman, S. A., 1996, Approximate inelastic procedures to identify failure mechanisms from higher mode effects, Proceedings of $11^{\text {th }}$ World Conference on Earthquake Engineering, Acapulco, Mexico, Paper No. 966.

Rodriguez, M. E., Restrepo, J. I., and Carr, A. J., 2002, Earthquake-induced floor horizontal accelerations in buildings, Earthquake Eng. Struct. Dyn. 31 (3), 693-718.

Sasaki, K. K., Freeman, S. A., and Paret, T. F., 1998, Multimode pushover procedure (MMP) - A method to identify the effects of higher modes in a pushover analysis, Proceedings of $6^{\text {th }}$ U.S. National Conference on Earthquake Engineering, Seattle, WA.

Somerville, P., Smith, N., Punyamurthula, S., and Sun, J., 1997. Development of ground motion time histories for Phase 2 of the FEMA/SAC steel project, SAC Background Document Report No. SAC/BD-9/04, SAC Joint Venture, Sacramento, CA.

Veletsos, A. S., and Newmark, N. M., 1960, Effect of inelastic behavior on the response of simple systems to earthquake motions, Proceedings of $2^{\text {nd }}$ World Conference on Earthquake Engineering, Japan, 2, pp. 895-912. 